\title{
Double dermal sinuses: a case study
} Mostafa El Khashab1, Farideh Nejat*2 and Abolhasan Ertiaei²

Address: ${ }^{1}$ Department of Neurosurgery, Hackensack University Medical Center, New Jersey, USA and ${ }^{2}$ Department of Neurosurgery, Children's Hospital Medical Center, Medical Sciences/University of Tehran, Tehran, Iran

Email: Mostafa El Khashab - mostkash@yahoo.com; Farideh Nejat* - nejat@sina.tums.ac.ir; Abolhasan Ertiaei - faridnejat@yahoo.com

* Corresponding author

Published: 26 August 2008

Journal of Medical Case Reports 2008, 2:28I doi:10.1 186/1752-1947-2-28I

This article is available from: http://www.jmedicalcasereports.com/content/2/1/28

(C) 2008 El Khashab et al; licensee BioMed Central Ltd.

This is an Open Access article distributed under the terms of the Creative Commons Attribution License (http://creativecommons.org/licenses/by/2.0), which permits unrestricted use, distribution, and reproduction in any medium, provided the original work is properly cited.
Received: 4 January 2008

Accepted: 26 August 2008

\begin{abstract}
Introduction: Dermal sinus tracts are rare congenital lesions located in the midline characterized by a cutaneous pit or dimple. They occur all along the midline neuroaxis, from the nasion and occipital area down to the lumbar and sacral regions, most frequently in the lumbar and lumbosacral region.
\end{abstract}

Case presentation: Here we report a 5-year-old girl who presented with occasional headache. There were two dimples, one on the dorsal aspect of her head and another on her neck.

Conclusion: Dermal sinuses are almost always singular and the co-existence of double dermal sinuses has not been reported previously.

\section{Introduction}

Dermal sinus tracts are rare congenital lesions located in the midline characterized by a cutaneous pit or dimple. They are defined as developmental anomalies in which the end result can be abnormal communication between the dermis and intracranial structures. They incorporate a tract of cutaneous ectoderm from the dorsal midline skin that extends for a variable distance into the underlying mesenchymal tissue and in many instances penetrates the dura to end within the thecal sac adjacent to, or continuous with the neural tube [1]. Sinuses may be asymptomatic or present clinically with varying degrees of drainage from their cutaneous openings, recurrent bouts of septic or aseptic meningitis, or mass effect on the cerebrospinal fluid (CSF) pathways and consequent hydrocephalus [2].

These lesions are almost always solitary and co-existence of double dermal sinuses has not been reported previ- ously. We report a girl with asymptomatic double dermal sinuses.

\section{Case presentation}

This 5-year-old girl presented with occasional headache. She was the first child of nonconsanguineous parents without significant past medical history. On physical examination, the child was totally normal neurologically and generally. There were two dimples on the dorsal aspect of her head and neck. A fine dimple was noted at the midline occipital area above the inion, surrounded by a small smooth hairless area, harboring a few thick black hairs at the ostium without any discharge (Fig. 1a). The other dimple was at the midcervical area with a large mouth and hemangiomatous skin discoloration around the dimple (Fig. 1b). Brain magnetic resonance imaging (MRI) was performed, which was normal without bone defect and intracranial sinus or tract. Cervical MRI showed the sinus at the level of the $\mathrm{C} 3-\mathrm{C} 4$ vertebra with a tract 
a

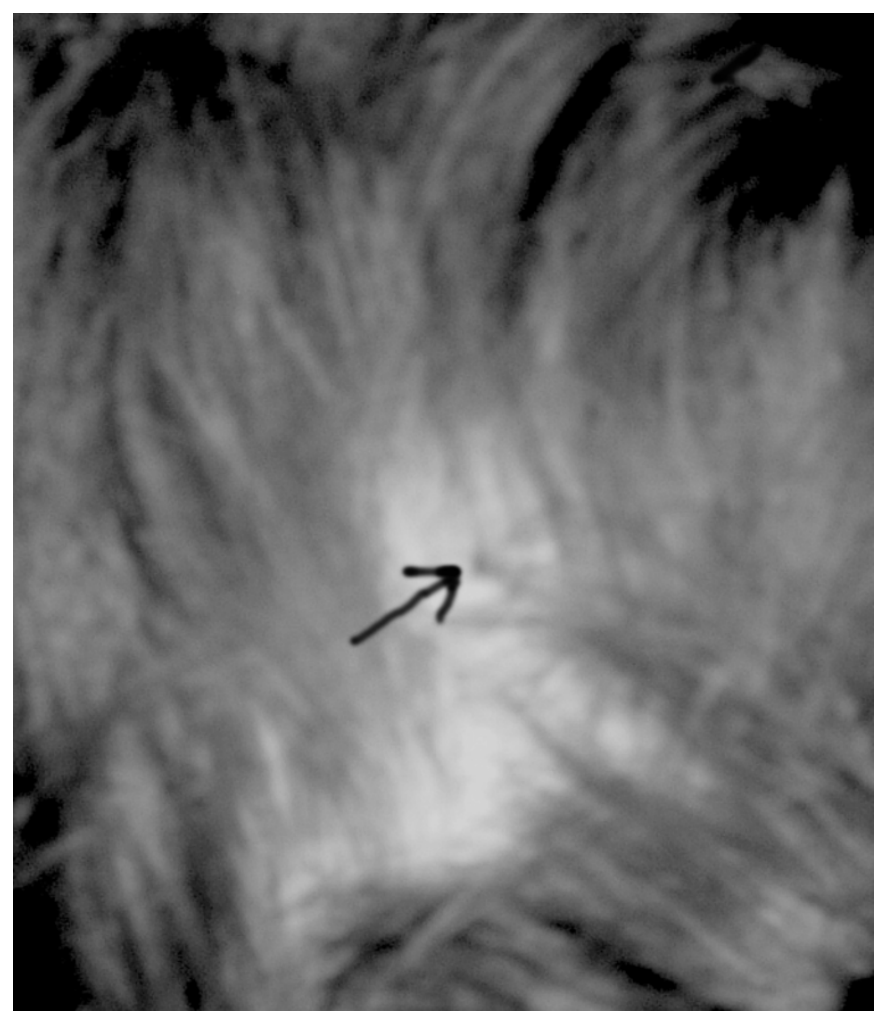

b

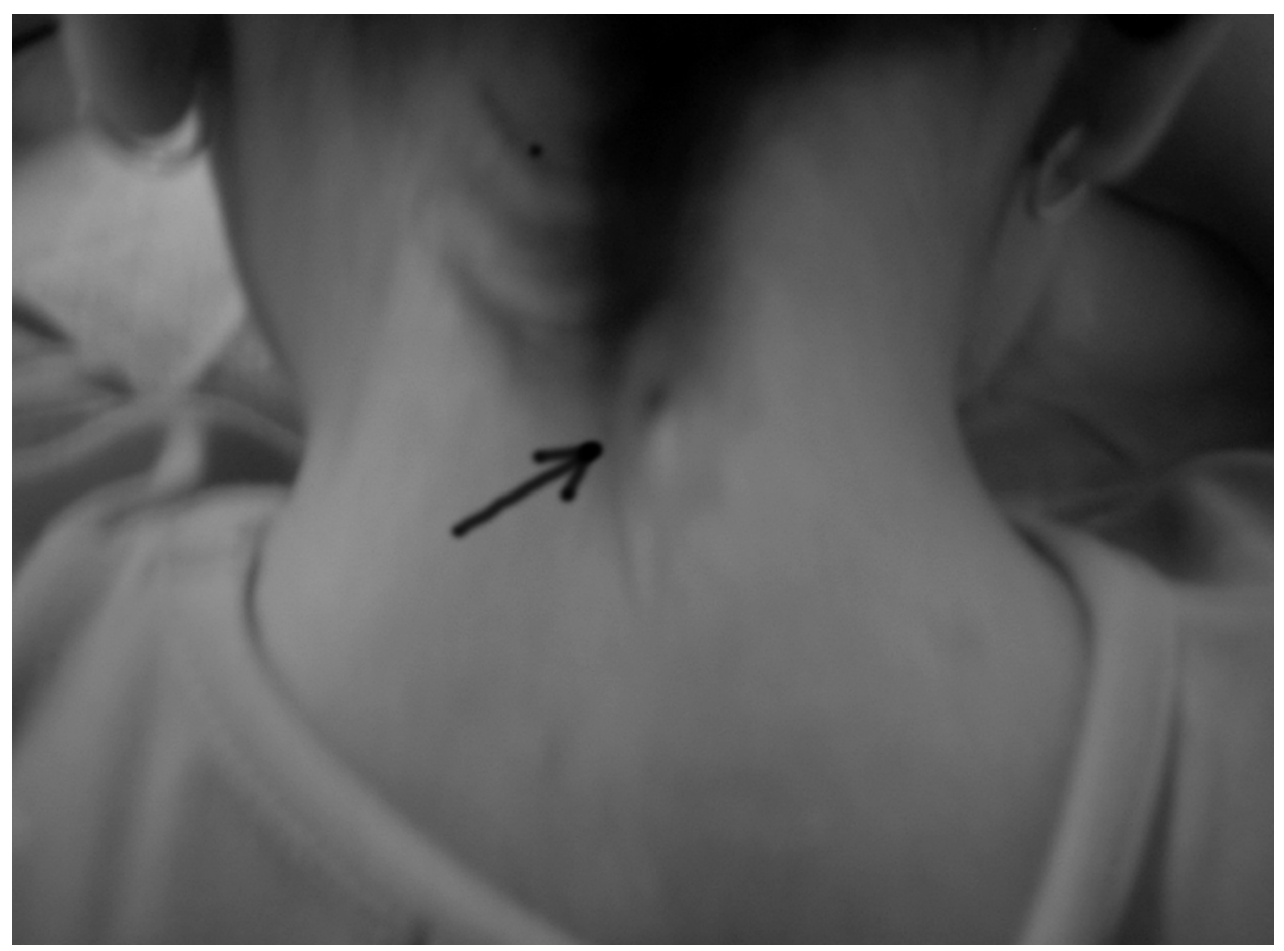

Figure I

A: Photograph (posterior view) of the child's head showing a small opening in the midline occipital area (arrow) above the occipital protuberance and B: midcervical area. 


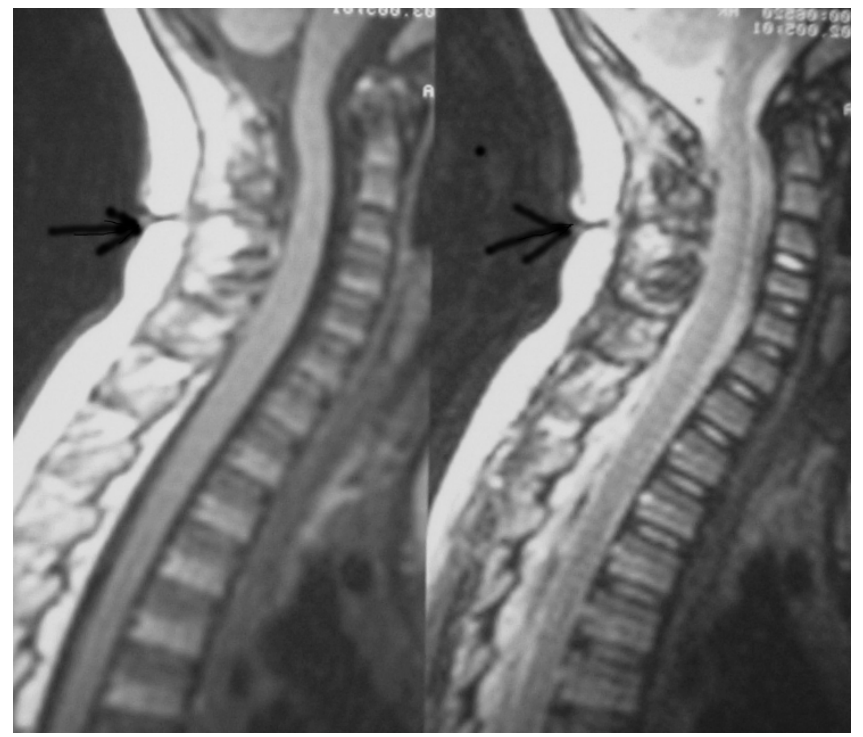

Figure 2

Sagittal T I-weighted MR image showing the opening of the dermal sinus at the level of C3-C4 and the extension of the tract outside the spinal canal.

ending before the spinal canal (Fig. 2). She had not experienced any previous infection and there was no intradural extension for both lesions, therefore further investigation or procedure was not done.

\section{Discussion}

Congenital dermal sinus is a rare entity $(1 / 2500)$, and consists of a tract lined by stratified squamous epithelium $[3,4]$. It is often detected at birth, and usually by the end of the first year. Typically, the pediatrician notes a midline dimple or cutaneous defect, containing one or more hairs [5].

The most widely accepted theory regarding the embryogenesis of dermal sinus tracts and related anomalies proposed that they arise through faulty separation of the neuroectoderm from the overlying cutaneous ectoderm at the time of dysjunction between the third and eighth week of gestation $[1,5,6]$.

They have been reported all along the midline neuroaxis, from the nasion and occipital area down to the lumbar and sacral regions [3], most frequently in the lumbar and lumbosacral region $(75 \%)$ and only $1 \%$ of all tracts along the spine are cervical $[6,7]$.

Cranial sinuses are less frequent than their counterparts in the spinal region in which $85 \%$ are located near the external protuberance of the occipital bone, $11 \%$ at the nasion and $5 \%$ at the posterior parietal area [2]. The sinus tract may end in subcutaneous tissue or extend any distance inward to its ultimate embryological terminus, which is the conus medullaris for lesions in the lumbosacral region or the central canal of the spinal cord for tracts at the thoracic or cervical level [3].

Approximately one-half of the tracts terminate in a dermoid $(83 \%)$ or epidermoid $(13 \%)$ cyst or a teratoma $(4 \%)$. The slow growth rate of these tumors often masks their presentation for years, although there are some patients with acute neurological deterioration $[3,8]$.

A wide spectrum of clinical manifestations can occur ranging from asymptomatic dermal sinus to serious complications. There is no apparent timeframe for an asymptomatic lesion to later become symptomatic [9]. This process is believed to be benign until an episode of meningitis [5]. Meningitis resulting from dermal sinus tracts may occur at any age and is seen in infants and elderly patients. Patients may present with concomitant infections of the dermal sinus tract and underlying inclusion cysts [8].

MRI has become the reference study technique because of its ability to accurately depict the extent of the sinus tract and associated lesions [8].

Therapy is almost always surgical. The goal is obliteration of the tract with elimination of the communication between the skin and the neural structures. The earlier the lesion is detected and corrected, the less likely any longterm morbidity [5].

The process of dysjunction occurs after closure of the neural tube at a time between the third and eighth week of gestation, whereas it develops during the third to fifth week of intrauterine life in the cranium. At the same time, the cutaneous portion of the neuroectoderm separates and fuses in the midline to form the overlying integument. Disorders of this process may lead to midline dermal anomalies such as dermal sinus tracts and inclusion cysts $[5,6,8]$.

\section{Conclusion}

We described a rare case of double dermal sinus. To our knowledge, there is no report of double or multiple dermal sinuses in the literature. Regarding the similar range of gestational age for dysjunction in the spinal and cranial neural tube, the occurrence of double dermal sinuses in one person, of which one is cranial and the other cervical, suggests that there is an underlying cause which affects separation of the neuroectoderm at an early gestational age during the third to eighth week of gestation. 


\section{Competing interests}

The authors declare that they have no competing interests.

\section{Authors' contributions}

All authors have contributed to the study and manuscript preparation.

\section{Consent}

Written informed consent was obtained from the patient's next of kin for publication of this case report and any accompanying images. A copy of the written consent is available for review by the Editor-in-Chief of this journal.

\section{References}

I. Ackerman LL, Meneses AH: Spinal congenital dermal sinuses: a 30 year experience. Pediatrics 2003, I | 2:64|-647.

2. Ansari S, Dadmehr M, Nejat F: Possible genetic correlation of an occipital dermal sinus in a mother and son. J Neurosurg 2006, I 05(4 Suppl):326-328.

3. Dias MS, McLone DG: Normal and abnormal early development of the nervous system. In Pediatric Neurosurgery: Surgery of Developing Nervous System Edited by: McLone DG. Philadelphia, PA: WB Saunders; 2001:31-7I.

4. Goodrich JT: Congenital scalp and skull defects. In The Practice of Neurosurgery Edited by: Tindal GT, Cooper PR, Barrow DL. Baltimore: Williams \& Wilkins; 1996:2647-2660.

5. James HE: Encephalocele, dermoid sinus, and arachnoid cyst. In Pediatric Neurosurgery: Surgery of Developing Nervous System Edited by: McLaurin R, Venes JL, Schut L, Epstein F. Philadelphia, PA: WB Saunders; 1989:97-105.

6. Jindal A, Mahapatra AK: Spinal congenital dermal sinus: an experience of 23 cases over 7 years. Neurol India 200I, 49:243-246.

7. McComb JG, Chen TC: Closed spinal neural tube defects. In The Practice of Neurosurgery Edited by: Tindal GT, Cooper PR, Barrow DL. Baltimore: Williams \& Wilkins; 1996:2754-2777.

8. Nejat F, Dias MS, Eftekhar B, Nasri Roodsari N, Hamidi S: Bilateral retro-auricular dermal sinus tracts with intradural extension. Case report. J Neurosurg 2003, 99:163-166.

9. Keating RF, Multani J, Cogen PH: Occult spinal dysraphism and the tethered spinal cord. In Youmans Neurological Surgery Edited by: Winn HR. Philadelphia, PA: WB Saunders; 2003:3257-3283.

Publish with Biomed Central and every scientist can read your work free of charge

"BioMed Central will be the most significant development for disseminating the results of biomedical research in our lifetime."

Sir Paul Nurse, Cancer Research UK

Your research papers will be:

- available free of charge to the entire biomedical community

- peer reviewed and published immediately upon acceptance

- cited in PubMed and archived on PubMed Central

- yours - you keep the copyright

Submit your manuscript here:

http://www.biomedcentral.com/info/publishing_adv.asp
BioMedcentral 